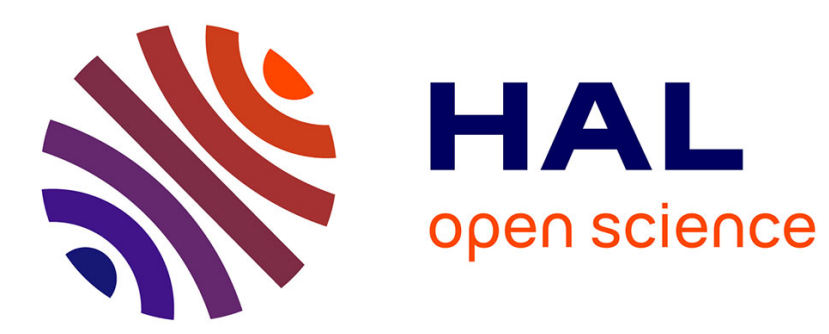

\title{
A Model Predictive approach for semi active suspension control problem of a full car
}

\author{
Manh Quan Nguyen, Massimo Canale, Olivier Sename, Luc Dugard
}

\section{To cite this version:}

Manh Quan Nguyen, Massimo Canale, Olivier Sename, Luc Dugard. A Model Predictive approach for semi active suspension control problem of a full car. CDC 2016 - 55th IEEE Conference on Decision and Control, Dec 2016, Las Vegas, NV, United States. pp. 721 - 726, 10.1109/CDC.2016.7798353 . hal-01361841

\section{HAL Id: hal-01361841 \\ https://hal.science/hal-01361841}

Submitted on 7 Sep 2016

HAL is a multi-disciplinary open access archive for the deposit and dissemination of scientific research documents, whether they are published or not. The documents may come from teaching and research institutions in France or abroad, or from public or private research centers.
L'archive ouverte pluridisciplinaire HAL, est destinée au dépôt et à la diffusion de documents scientifiques de niveau recherche, publiés ou non, émanant des établissements d'enseignement et de recherche français ou étrangers, des laboratoires publics ou privés. 


\title{
A Model Predictive approach for semi active suspension control problem of a full car
}

\author{
M.Q.Nguyen $^{1 *}$, M.Canale ${ }^{2}$, O.Sename ${ }^{1}$, L.Dugard ${ }^{1}$
}

\begin{abstract}
A suspension controller aims at enhancing the ride comfort and the handling of vehicle which are evaluated by the acceleration at center of gravity and the roll motion resspectively. In this paper, a semi-active suspension Model Predictive Control (MPC) is designed for a full vehicle system equipped with 4 semi-active dampers. The main challenge in the semi-active suspension control problem is to tackle with the dissipativity constraints of the semi-active dampers , here recasted as input and state constraints. The controller is designed in the MPC framework where the effects of the unknown road disturbances are taken into account. An observer approach allows to estimate the road disturbance information to be used by the controller during the prediction step. Then, the MPC control law with road estimation (but without road preview) is computed by minimizing a quadratic cost function, giving a trade-off between the comfort and the handling, while guaranteeing some phyiscal constraints of the semi-active dampers. Some simulation results performed on a nonlinear full car model are presented in order to illustrate the effectiveness of the proposed approach.
\end{abstract}

Keywords: Semi-active suspension, road disturbance estimation, MPC control, Input Constraints.

\section{INTRODUCTION}

The suspension system plays a key role in enhancing the vehicle performances with regard to ride comfort and road handling. Semi-active suspensions are today more and more used in automotive industry because of their efficiency, while being less expensive and comsumming less energy than pure active suspensions. However, the main challenge of semi-active suspension control problems is to handle the dissipativity constraints of semi-active dampers. Several control design problems have then been tackled with many different approaches. [1], [2] give extensive surveys on semi active suspension control. In more detail, [3] proposed a classical control method based on the Skyhook control to improve the ride comfort. Then, several extensions of skyhook control have been presented in the past decades as in [4], or [5] where Mixed Skyhook-ADD is proposed. More recently, some modern control approaches have been suggested. [6] proposed an LQ-based clipped optimal control. Some LPV techniques for semi-active suspension control problems have been presented as in [7], [8] or [9] used an LPV approach with sector condition to deal with

1 Univ. Grenoble Alpes, Control System Department, GIPSA-lab, F-38000 Grenoble, France CNRS, GIPSA-lab, F-38000 Grenoble, France. $\{$ manh-quan.nguyen, olivier.sename, luc.dugard\}@gipsa-lab.grenoble-inp. fr

2 Dipartimento di Automatica e Informatica, Politecnico di Torino, Corso Duca degli Abruzzi 24 - 10129 Torino - Italy. massimo. canale epolito.it the dissipativity constraints of semi-active dampers.

Regarding the actuator saturation control problem, Model Predictive Control allows to explicitly take into account the effect of input and state constraints in the control design step. Several works have employed the MPC approach for semiactive suspension systems. Nevertheless most of the studies considered a quarter-car model only. Let us mention here [10] where the constrained quarter-car semi-active suspension is modelled as a switching affine system and the MPC controller is computed thanks to a mixed-integer quadratic programming. In [11], a fast MPC is designed for a half car model, but the MPC controller is still designed based on a quarter car suspension model. Moreover, the effects of disturbances are not taken into account in the prediction horizon. [12] proposes a methodology for optimal semiactive suspension system based on MPC approach for a quarter car model while assuming that the road disturbance is measured in advance and used in the prediction horizon. However, the quarter car model equipped with one semiactive damper which is not enough to express the full dynamic of the vehicle with four semi-active dampers. In order to deal with the full car model case, one possibility is to design four seperated controllers at the four corners. However, by this way, the effects of the coupling and the load transfer distribution between the corners during various driving situations (cornering, steering, accelerating, and braking...) may not be considered, which could lead to lower performance.

Concerning the full car dynamics, up to the authors knowledge, very few studies have been proposed to develop MIMO MPC semi-active control techniques. [13] employs a nonlinear programming approach (not suitable for implementation). To overcome such a problem, [13] introduces an approximate descripition of the constraints as well as the clipping of the control action. On the other hand, taking into account the disturbances during the prediction horizon gives a better efficiency for the predictive control. [14] uses the road profile preview by means of expensive and not standard sensors (e.g. camera) for the case of active suspension. Disturbance estimation is not used, except in a case, to verify the preview obtained by the camera and also in the context of active suspension.

In this work, a semi-active suspension MPC controller is designed for a full vehicle model equipped with 4 semi-active dampers. The proposed solution integrates a state feedback control with an observer of the vehicle state variables and of 
the road disturbance. The paper contributions are twofolds:

- An observer approach is proposed to estimate both the system state (needed anyway by all MPC approaches) and road disturbances. It is woth mentioning that while the estimation of the road inputs allow to improve the efficiency of the predictive controller, it is here obtained using standard sensors and then differs from the preview approach.

- A MPC suspension control with road disturbance estimation (but without road preview) is obtained by optimimizing a quadratic cost function. This cost describes the ride comfort and road holding performances, while ensuring the dissipativity constraints of the semi-active dampers. The controller solution is derived within the mixed integer quadratic programming (MIQP). Such an approach allows online implemention of the solution. The results are compared to those obtained by MPC with disturbance preview and by MPC without taking into account the disturbance during the prediction; they show the interest of the proposed approach.

The structure of the paper is given as follows. Section II describes a full vertical vehicle model and the problem formulation. Section III presents the semi-active suspension control design using MPC. Section IV presents the obsever design for state and road disturbance estimation. Some simulation results are given in the section V. Finally, some conclusions are drawn in the section VI.

\section{A FULL CAR MODEL EQUIPPED WITH 4 SEMI-ACTIVE SUSPENSIONS}

\section{A. Full car model}

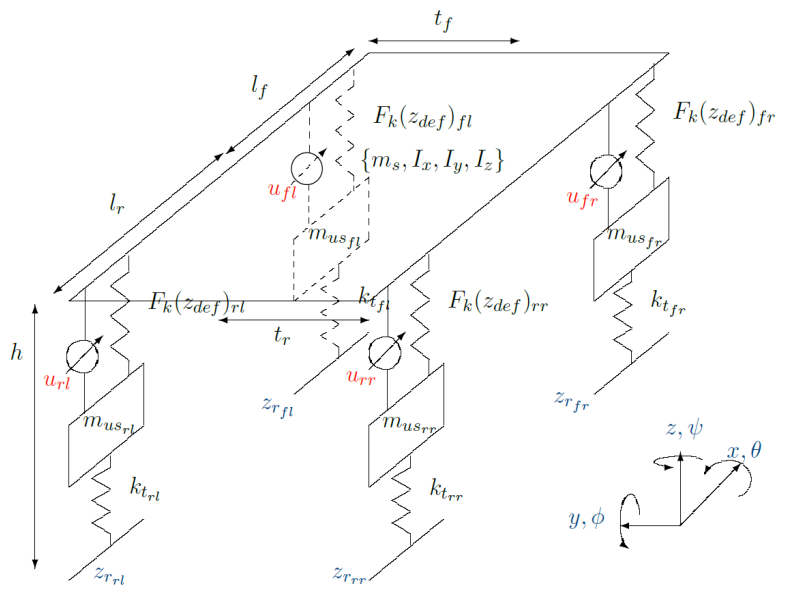

Fig. 1. A full vehicle model

A full car vertical model is used for the analysis and control of the vehicle dynamic behavior. This is a classical 7 degree of freedom (DOF) suspension model, obtained from a nonlinear full vehicle model (referred in [15]). This model not only involves the chassis dynamics (vertical $\left(z_{s}\right)$, roll $(\theta)$ and pitch $(\phi))$, but it also figures out $\left(z_{u s_{i j}}\right)$ the vertical displacements of the wheels at the front/rear $(i=(f, r))$ - left/right corner $(j=(l, r))$. The vertical 7DOF full-car model is governed by the following equations:

$$
\left\{\begin{array}{l}
m_{s} \ddot{z}_{s}=-F_{s f l}-F_{s f r}-F_{s r l}-F_{s r r} \\
I_{x} \ddot{\theta}=\left(-F_{s f r}+F_{s f l}\right) t_{f}+\left(-F_{s r r}+F_{s r l}\right) t_{r} \\
I_{y} \ddot{\phi}=\left(F_{s r r}+F_{s r l}\right) l_{r}-\left(F_{s f r}+F_{s f l}\right) l_{f} \\
m_{u s} \ddot{z}_{u s_{i j}}=-F_{s_{i j}}+F_{t z_{i j}}
\end{array}\right.
$$

where $I_{x}, I_{y}$ are the moments of inertia of the sprung mass around the longitudinal and lateral axis respectively, $h$ is the height of center of gravity (COG). $l_{f}, l_{r}, t_{f}, t_{r}$ are COG-front, rear, left, right distances respectively.

$F_{t z_{i j}}$ are the vertical tire forces, given as:

$$
F_{t z_{i j}}=-k_{t_{i j}}\left(z_{u s_{i j}}-z_{r_{i j}}\right)
$$

where $k_{t_{i j}}$ are the stiffness coefficients of the tires, and $z_{r_{i j}}$ the road profiles.

The vertical suspension forces $F_{s_{i j}}$ at the 4 corners of the vehicle are modeled by a spring and a damper with non linear characteristics for simulation, and linear ones for control design. The equation (3) allows to model the suspension force used in the control design step:

$$
F_{s_{i j}}=k_{i j}\left(z_{s_{i j}}-z_{u s_{i j}}\right)+F_{d_{i j}}
$$

where $k_{i j}$ is the nominal spring stiffness coefficient, and $z_{s_{i j}}$ is the chassis position at each corner, and $F_{d_{i j}}$ is the semiactive controlled damper force given by:

$$
F_{d_{i j}}=c_{i j}(.) \dot{z}_{d e f_{i j}}=c_{i j}(.)\left(\dot{z}_{s_{i j}}-\dot{z}_{u s_{i j}}\right)
$$

where $c_{i j}($.$) the damping coefficient is assumed to be varying$ for control purpose. To ensure the dissipativity constraint of each semi-active damper, the following constraint must be considered:

$$
0 \leqslant c_{\min _{i j}} \leqslant c_{i j}(.) \leqslant c_{\text {max }_{i j}}
$$

Now, let us rewrite the damper force (4) as follows:

$$
F_{d_{i j}}=c_{n o m_{i j}} \dot{z}_{d e f_{i j}}+u_{i j}
$$

where $c_{n o m_{i j}}=\left(c_{\text {max }_{i j}}+c_{\text {min }_{i j}}\right) / 2$ is the nominal damping coefficient, $u_{i j}$ is the incremental force and is considered as the control input. Then the equation (3) becomes:

$$
F_{s_{i j}}=k_{i j}\left(z_{s_{i j}}-z_{u s_{i j}}\right)+c_{n o m_{i j}}\left(\dot{z}_{s_{i j}}-\dot{z}_{u s_{i j}}\right)+u_{i j}
$$

where the sprung mass positions $z_{s_{i j}}$ at each corner of the vehicle can be easily derived from the vehicle equations of motions, and given by:

$$
\left\{\begin{array}{l}
z_{s_{f l}}=z_{s}-l_{f} \sin \phi+t_{f} \sin \theta, \\
z_{s_{f r}}=z_{s}-l_{f} \sin \phi-t_{f} \sin \theta, \\
z_{s_{r l}}=z_{s}+l_{r} \sin \phi+t_{r} \sin \theta, \\
z_{s_{r r}}=z_{s}+l_{r} \sin \phi-t_{r} \sin \theta,
\end{array}\right.
$$

Assuming that the roll and pitch angles are small enough, these nonlinear equations are linearized by:

$$
\left\{\begin{array}{l}
z_{s_{f l}}=z_{s}-l_{f} \phi+t_{f} \theta, \\
z_{s_{f r}}=z_{s}-l_{f} \phi-t_{f} \theta, \\
z_{s_{r l}}=z_{s}+l_{r} \phi+t_{r} \theta \\
z_{s_{r r}}=z_{s}+l_{r} \phi-t_{r} \theta,
\end{array}\right.
$$

By substituting the tire force equations (2) and the suspension force equations (7) into the vehicle equations (1), then the 
following state-space representation with 14 state variables is given by:

$$
\left\{\begin{array}{l}
\dot{x}(t)=A x(t)+B_{1} w(t)+B_{2} u(t) \\
y(t)=C x(t)+D_{1} w(t)+D_{2} u(t)
\end{array}\right.
$$

where

$$
\left\{\begin{array}{c}
x=\left[z_{s}, \theta, \phi, z_{u s f l}, z_{u s f r}, z_{u s r l}, z_{u s r r}, \dot{z}_{s}, \dot{\theta}, \dot{\phi},\right. \\
\left.\dot{z}_{u s f l}, \dot{z}_{u s f r}, \dot{z}_{u s r l}, \dot{z}_{u s r r}\right] \\
u=\left[u_{f l}, u_{f r}, u_{r l}, u_{r r}\right] \\
w=\left[z_{r f l}, z_{r f r}, z_{r r l}, z_{r r r}\right] \\
y=\left[\ddot{z}_{s f l}, \ddot{z}_{s f r}, \ddot{z}_{s r l}, \ddot{z}_{s r r}, z_{u s f l}, z_{u s f r}, z_{u s r l}, z_{u s r r}\right]
\end{array}\right.
$$

are the state, the control input vector, the disturbance inputs, and output measurements vectors respectively. $A, B_{1}, B_{2}, C, D_{1}, D_{2}$ are matrices of the state space representation.

Since in the MPC approach, the optimization problem must be described in discrete time domain, then for this purpose, the continuous time model (10) has been discretized with a sampling time $T_{S}$ using for example the zero order hold method. The obtained discrete time model is denoted as follows:

$$
\begin{aligned}
x_{k+1} & =A_{d} x_{k}+B_{1 d} w_{k}+B_{2 d} u_{k} \\
y_{k} & =C_{d} x_{k}+D_{1 d} w_{k}+D_{2 d} u_{k}
\end{aligned}
$$

where $A_{d}, B_{1 d}, B_{2 d}, C_{d}, D_{1 d}, D_{2 d}$ are matrices of the state space representation.

\section{B. Input constraints}

The dissipativity conditions of the semi-active damper given in (5) is here transformed into input constraints. Note that from (5-6), it follows that:

$$
\begin{array}{lll}
c_{\text {min }_{i j}} \dot{z}_{d e f_{i j}} \leq F_{d_{i j}} \leq c_{\text {max }_{i j}} \dot{z}_{d e f_{i j}} & \text { if } & \dot{z}_{d e f_{i j}} \geq 0 \\
c_{\text {max }_{i j}} \dot{z}_{d e f_{i j}} \leq F_{d_{i j}} \leq c_{\text {min }_{i j}} \dot{z}_{d e f_{i j}} & \text { if } & \dot{z}_{d e f_{i j}}<0
\end{array}
$$

The dissipativity constraint is now recast into:

$$
\begin{gathered}
c_{\text {min }_{i j}} \dot{z}_{d e f_{i j}} \leq c_{\text {nom }_{i j}} \dot{z}_{d e f_{i j}}+u_{i j} \leq c_{\text {max }_{i j}} \dot{z}_{d e f_{i j}} \quad \text { if } \quad \dot{z}_{d e f_{i j}} \geq 0 \\
c_{\text {max }_{i j}} \dot{z}_{d e f_{i j}} \leq c_{\text {nom }_{i j}} \dot{z}_{d e f_{i j}}+u_{i j} \leq c_{\text {min }_{i j}} \dot{z}_{d e f_{i j}} \quad \text { if } \quad \dot{z}_{d e f_{i j}}<0 \\
\text { Since } c_{n o m_{i j}}=\frac{\left(c_{\max _{i j}}+c_{\text {min }_{i j}}\right)}{2}, \text { we must have: } \\
\left|u_{i j}\right| \leq \frac{\left(c_{\max _{i j}}-c_{\text {min }_{i j}}\right)}{2}\left|\dot{z}_{\text {def }}\right|
\end{gathered}
$$

Or equivalently, for $i$ corresponds to front/rear and $j$ to left/right:

$$
\begin{aligned}
& \text { if } \dot{z}_{d e f_{i j}} \geq 0 \text {, then }\left\{\begin{array}{l}
u_{i j} \geq \frac{\left(c_{m_{i n} n_{i j}}-c_{\max _{i j}}\right)}{2}\left(\dot{z}_{s_{i j}}-\dot{z}_{u s_{i j}}\right) \\
u_{i j} \leq \frac{\left(c_{\max _{i j}}-c_{\min _{i j}}\right)}{2}\left(\dot{z}_{s_{i j}}-\dot{z}_{u s_{i j}}\right)
\end{array}\right. \\
& \text { if } \dot{z}_{d e f_{i j}}<0 \text {, then }\left\{\begin{array}{l}
u_{i j} \geq \frac{\left(c_{\max _{i j}}-c_{\min _{i j}}\right)}{2}\left(\dot{z}_{s_{i j}}-\dot{z}_{u s_{i j}}\right) \\
u_{i j} \leq \frac{\left(c_{\min _{i j}}-c_{\max _{i j}}\right)}{2}\left(\dot{z}_{s_{i j}}-\dot{z}_{u s_{i j}}\right)
\end{array}\right.
\end{aligned}
$$

The dissipativity constraint (15) can be expressed as a set of linear inequalites between the control input $u_{i j}$ and the state variables $x$. Actually, $\dot{z}_{d e f_{i j}}=\dot{z}_{s_{i j}}-\dot{z}_{u s_{i j}}$ is a linear combination of the system state $x$, i.e $\dot{z}_{d e f_{i j}}=\dot{z}_{s_{i j}}-\dot{z}_{u s_{i j}}=$ $C_{i n} x$, where $C_{i n}$ is an appropriate matrix. Thus, in the discrete time domain, the control input $u_{i j_{k}}$ must satisfy the following constraints:

$$
\begin{aligned}
& \text { if } C_{i n} x_{k} \geq 0,\left\{\begin{array}{l}
u_{i j_{k}} \geq \frac{\left(c_{\min _{i j}}-c_{\max _{i j}}\right)}{2} C_{i n} x_{k} \\
u_{i j_{k}} \leq \frac{\left(c_{\max _{i j}}-c_{\left.\min _{i j}\right)}\right)}{2} C_{i n} x_{k}
\end{array}\right. \\
& \text { if } C_{i n} x_{k}<0,\left\{\begin{array}{l}
u_{i j_{k}} \geq \frac{\left(c_{\max _{i j}}-c_{\min _{i j}}\right)}{2} C_{i n} x_{k} \\
u_{i j_{k}} \leq \frac{\left(c_{\min _{i j}}-c_{\max _{i j}}\right)}{2} C_{i n} x_{k}
\end{array}\right.
\end{aligned}
$$

\section{SEMI-ACtIVE SUSPENSION CONTROL USING MPC}

\section{A. Performance index}

The main objective of the suspension in the vehicle system is to isolate the body (comfort performance) from the road disturbances, without deteriorating the road holding (handling performance). Comfort and handling performance can be described through vehicle center of gravity heave acceleration $\ddot{z}_{s}$ and roll angle $\theta$ respectively ([16]). In particular, the following performance indices can be considered:

$$
\begin{gathered}
J_{\text {comfort }}=\int_{0}^{T} \ddot{z}_{s}^{2}(t) d t \\
J_{\text {handling }}=\int_{0}^{T} \theta^{2}(t) d t
\end{gathered}
$$

However, it is a well known fact that (17) and (18) are conflicting objectives. For this reason, a control law has to be designed in order to optimize the overall performance through a suitable trade-off between (17) and (18) and taking into account the dissipativity constraint (15). The semiactive suspension control problem can be formulated as a constrained optimization problem that can be casted in the well known framework of Model Predictive Control (MPC), see e.g [17].

In this regard, by defining $N_{p}$ as the prediction horizon, the following cost function is chosen as the performance index to be minimized:

$$
J\left(U, N_{p}, x_{k \mid k}\right)=\sum_{i=0}^{N_{p}-1}(1-\rho)\left(\ddot{z}_{k+i \mid k}^{s}\right)^{2}+\rho\left(\theta_{k+i \mid k}\right)^{2}
$$

where $\ddot{z}_{k+i \mid k}^{s}, \theta_{k+i \mid k}$ denote the chassis acceleration and roll angle predicted by using the model (11), given the initial state $x_{k \mid k}$, and $U=\left[u_{k \mid k}, u_{k+1 \mid k}, \ldots, u_{k+N_{p}-1 \mid k}\right]$ is the vector of the control moves to be optimized. $\rho \in\left[\begin{array}{ll}0 & 1\end{array}\right]$ is a weighting coefficient which can be tuned to achieve a suitable trade-off between comfort and handling performance.

It is worth mentionning that the tuning of the design parameter $\rho$ can be usually obtained through a sequence of trial and error steps. However, in this work, an alternative approach is proposed which consists in considering $\rho$ as the Load Transfer Ratio (LTR) of the vehicle. Actually, LTR can be computed by evaluating of the roll load transfer while the vehicle is running. As soon as there exists a load transfer from the left to the right or vice-versa, it means that the vehicle is faced to roll motion. By defining the vertical forces acting on the left and right sides by $F_{z l}$ and $F_{z r}$ respectively, we have:

$$
\left\{\begin{array}{l}
F_{z_{l}}=m_{s} \frac{g}{2}+m_{s} h \frac{a_{y}}{l_{f}} \\
F_{z_{r}}=m_{s} \frac{g}{2}-m_{s} h \frac{d_{y}}{l_{r}}
\end{array}\right.
$$


that allows us to introduce the LTR as:

$$
\rho:=\left|\frac{F_{z_{l}}-F_{z_{r}}}{F_{z_{l}}+F_{z_{r}}}\right|
$$

where $a_{y}$ is the lateral acceleration of the vehicle at center of gravity. Note that the LTR ratio can be evaluated online through the measurement of the lateral acceleration $a_{y}$. Since $\rho \in\left[\begin{array}{ll}0 & 1\end{array}\right]$, when $\rho \rightarrow 0$, there is neither lateral load transfer, nor roll motion, i.e the cost function (19) minimizes the chassis acceleration, aiming at improving the comfort performance. On the other hand, when $\rho \rightarrow 1$, the vehicle is within a critical situation caused by the roll motion. In this case, the roll motion in (19) needs to be weighted in order to improve the road holding performance.

\section{B. Optimisation problem setup}

Following the previous definitions, the optimization problem of the MPC design can be defined as:

$$
\begin{aligned}
& \min _{U} J\left(U, N_{p}, x_{k}\right) \\
& \text { s.t }\left\{\begin{array}{c}
x_{k+1}=A_{d} x_{k}+B_{1 d} w_{k}+B_{2 d} u_{k} \\
\text { dissipativity constraint (16) }
\end{array}\right.
\end{aligned}
$$

In order to compute the control action in the MPC framework, the cost function $J$ in (19) has to be evaluated along the state trajectory, within the prediction horizon, using the state equation (11). In this regard, given the available measurements described in section II at each sampling time, the system state has to be estimated using a suitable observer. Regarding the disturbance contribution, differently from [13], it is not assumed that road profile preview measurements can be obtained using a camera. Thus, to be able to account for the disturbance effect during the prediction, an extended state observer is designed, considering exisiting standard sensors, allowing to estimate the road input and the state variables simultaneously. In this way, the overall state equation employed for both prediction and state estimation. To this aim, a disturbance model is needed. One of the most common assumption in MPC design is that the disturbance is considered to be constant during the prediction horizon, i.e $w_{k+i}=w_{k}, i=0 \ldots N_{p}-1$. In this way, the following augmented state space model can be considered in the optimization problem (22):

$$
\left\{\begin{array}{c}
{\left[\begin{array}{l}
x_{k+1} \\
w_{k+1}
\end{array}\right]=\left[\begin{array}{cc}
A_{d} & B_{1 d} \\
0 & I
\end{array}\right]\left[\begin{array}{l}
x_{k} \\
w_{k}
\end{array}\right]+\left[\begin{array}{c}
B_{2 d} \\
0
\end{array}\right] u_{k}} \\
y_{k}=\left[\begin{array}{ll}
C_{d} & D_{1 d}
\end{array}\right]\left[\begin{array}{l}
x_{k} \\
w_{k}
\end{array}\right]+\left[\begin{array}{c}
D_{2 d} \\
0
\end{array}\right] u_{k}
\end{array}\right.
$$

The optimzation problem (22) now becomes:

$$
\min _{U} J\left(U, N_{p}, x_{k}\right)
$$

subject to (23) and constraint (16)

The MPC control law is then computed by applying the receding horizon strategy, where only the first element of the sequence $U$ is applied as the actual control action $u_{k}=u_{k \mid k}$. On the other hand, the dissipativity constraint (16) is defined in a way where the control input signal depends on the sign of the predicted state, especially the suspension deflection speed $C_{i n} x_{k}$. Therefore, the switching between the constraints according to the sign of $C_{i n} x_{k}$ must be satisfied. To this aim, the optimization problem (24) can be formulated as a quadratic problem involving logic constraints. In this regard, the optimization procedure is a mixed integer quadratic programming (MIQP) problem ([18]). Thanks to YALMIP [19] and using GUROBI optimisation solver [20], the optimal control law can be computed.

\section{STATE AND ROAD DistURbANCE ESTIMATION}

This section presents the observer design methodology. Within available measurements described in section II, the observability condition of the augmented system (23) is satisfied. Then, both the system state and road disturbances can be estimated by using an extended observer with the following structure:

$$
\left\{\begin{aligned}
{\left[\begin{array}{c}
\hat{x}_{k+1} \\
\hat{w}_{k+1}
\end{array}\right] } & =A_{o}\left[\begin{array}{l}
\hat{x}_{k} \\
\hat{w}_{k}
\end{array}\right]+B_{2 o} u_{k}-L\left(y_{k}-\hat{y}_{k}\right) \\
\hat{y}_{k} & =C_{o}\left[\begin{array}{c}
\hat{x}_{k} \\
\hat{w}_{k}
\end{array}\right]+\left[\begin{array}{c}
D_{2 d} \\
0
\end{array}\right] u_{k}
\end{aligned}\right.
$$

where $L$ is the observer gain to be designed and $A_{o}=\left[\begin{array}{cc}A_{d} & B_{1 d} \\ 0 & I\end{array}\right] ; B_{2 o}=\left[\begin{array}{c}B_{2 d} \\ 0\end{array}\right] ; C_{o}=\left[\begin{array}{cc}C_{d} & D_{1 d}\end{array}\right]$.

Let us define the estimation error of the augmented system: $e_{k}=\left[\begin{array}{l}x_{k} \\ w_{k}\end{array}\right]-\left[\begin{array}{l}\hat{x}_{k} \\ \hat{w}_{k}\end{array}\right]$

Then, the estimation error can be inferred from (23) and (25) as:

$$
e_{k+1}=A_{o}\left(\left[\begin{array}{l}
x_{k} \\
w_{k}
\end{array}\right]-\left[\begin{array}{l}
\hat{x}_{k} \\
\hat{w}_{k}
\end{array}\right]\right)-L C_{o}\left(\left[\begin{array}{l}
x_{k} \\
w_{k}
\end{array}\right]-\left[\begin{array}{l}
\hat{x}_{k} \\
\hat{w}_{k}
\end{array}\right]\right)
$$

Finally, one has:

$$
e_{k+1}=\left(A_{o}-L C_{o}\right) e_{k}
$$

Therefore, the observer design consists in calculating observer gain $L$ that ensures that the matrix $A_{o}-L C_{o}$ is Hurwitz. This can be calculated thanks to the pole placement approach within the poles of the extended observer are chosen around 5 to 10 times faster than the closed-loop system, so that the state estimation is good as early as possible.

First simulation results are here presented to assess the observer performance. In Figure 2, the estimated road profiles are a different standardized roads (ISO 8608). Note that here only the result of the estimated road profile under the front left wheel is shown, but the road profiles at four corners have been estimated correctly.

Remark: Note that, due to the presence of the state observer (25) a suitable robust MPC design method that explicitly takes into account the state estimation error should be adopted. In this regard, a possible solution is made up by the method introduced in [21], where a constraint tightening approach is adopted to deal with the state uncertainty induced by the observer. However, such an approach leads to a more conservative design procedure that may carry to unfeasibility issues of the optimization problem as well as a slight performance degradation. For this reason, similarly as done in [11] and [22], the MPC design will be performed without 


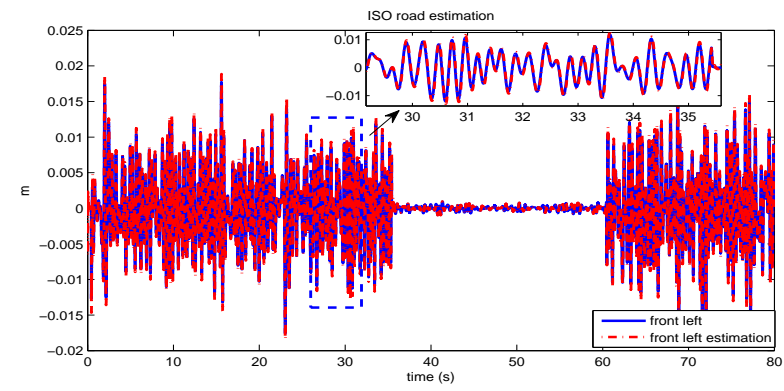

Fig. 2. Road estimation at front left conrner

taking explicitly into account the effects of estimation errors, thus exploiting its inherent robustness properties. As it will be seen in section $\mathrm{V}$, the proposed approach is able to provide quite good overall performance while satisfying the dissipativity constraint.

\section{Simulation Results}

To assess the proposed observer-controller strategy, simulations are performed on a full non linear vehicle model [15] with non linear suspension forces, validated on a Renault Mégane Coupé. The simulations are performed with a sampling time $T_{s}=0.005 \mathrm{~s}$, and a prediction horizon $N_{p}=10$. The following scenario is used to test the effectiveness of the proposed hybrid MPC controller:

- The vehicle runs at $120 \mathrm{~km} / \mathrm{h}$ in a straight line on dry road ( $\mu=1, \mu$ the adherence to the road).

- A $5 \mathrm{~cm}$ bump occurs simultaneously on the left and right wheels (from $t=0.5 \mathrm{~s}$ to $t=1 \mathrm{~s}$ ) to excite the bounce motion and chassis vibration.

- A $5 \mathrm{~cm}$ bump on the left wheels (from $t=2 \mathrm{~s}$ to $t=2.5 \mathrm{~s}$ ) causes the roll motion.

Firstly, Fig. 3 shows that the road profiles are well estimated using the proposed observer approach. This estimated road profiles are used for MPC design.
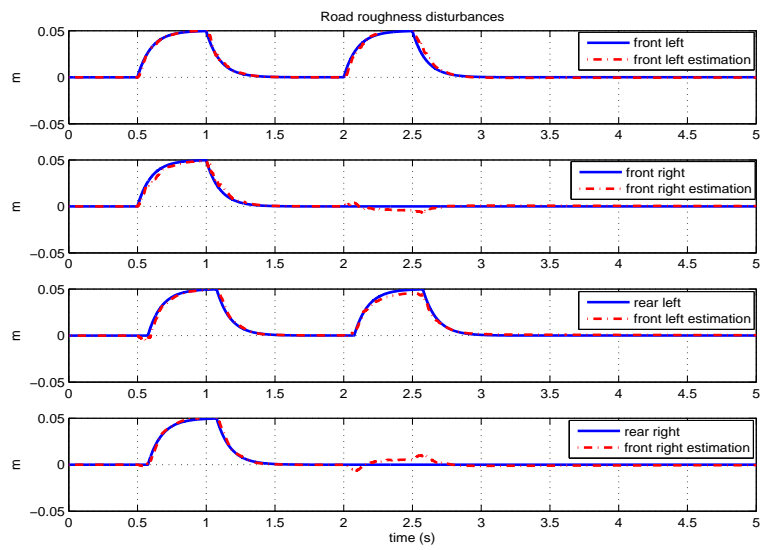

Fig. 3. Road profiles and their estimations

To demonstrate the efficiency of the proposed approach, we show a comparison results of the following control strategies:
- MPC with road disturbance estimation, called Proposed $M P C$

- MPC without taking into account the road disturbance during the prediction horizon, called MPC without $w$

- MPC with road disturbance preview, called MPC preview $w$

- Uncontrolled passive suspensions (i.e $u_{i j}=0$ ), called Nominal damper

Note that for MPC preview $w$, it is to be assumed the road disturbances are known in advance during the prediction horizon $N_{p}$.

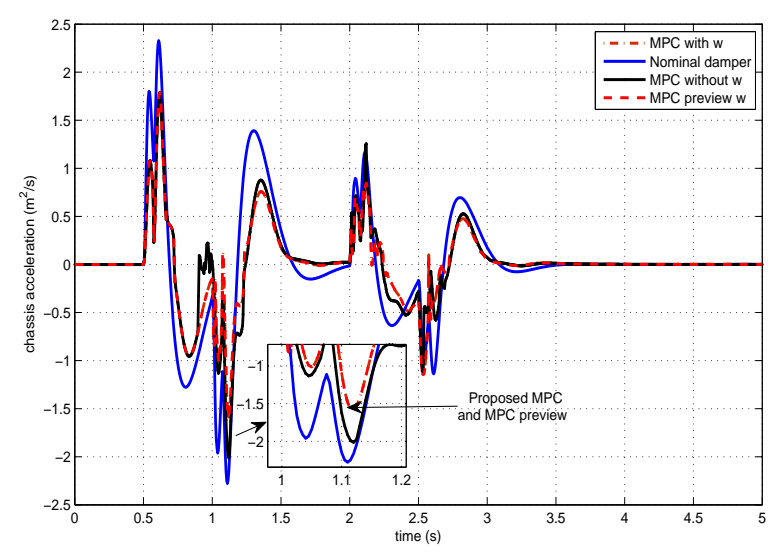

Fig. 4. Chassis acceleration

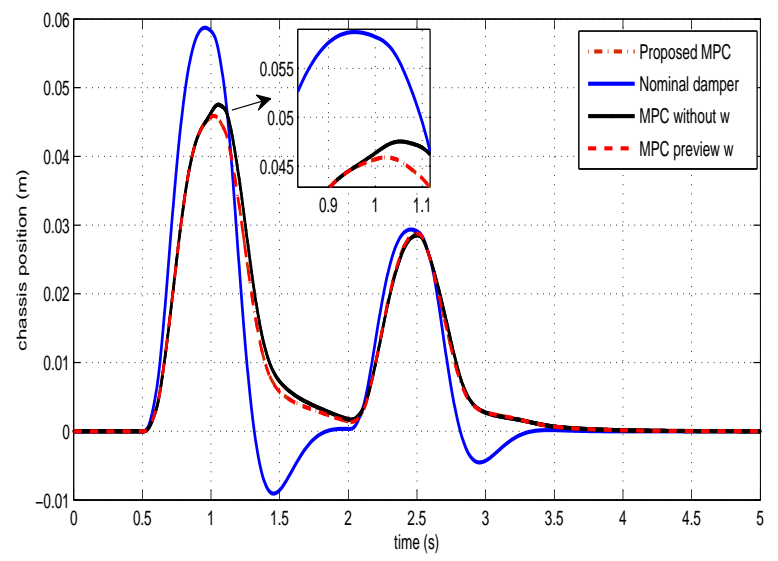

Fig. 5. Chassis position

Fig.4 shows the vehicle center of gravity heave acceleration. It can be seen that, within Proposed MPC the ride comfort of the vehicle behaves much better compared to Uncontrolled passive suspension case (Nominal damper). Moreover, Proposed MPC and MPC preview $w$ have almost the same performance and have some improvements with respect to $M P C$ without $w$. Fig 5 shows the chassis position response. Proposed MPC provides a better performance than MPC without $w$, Nominal damper.

Fig. 6 shows that Proposed MPC improves the road holding performance compared to Nominal damper. when one 


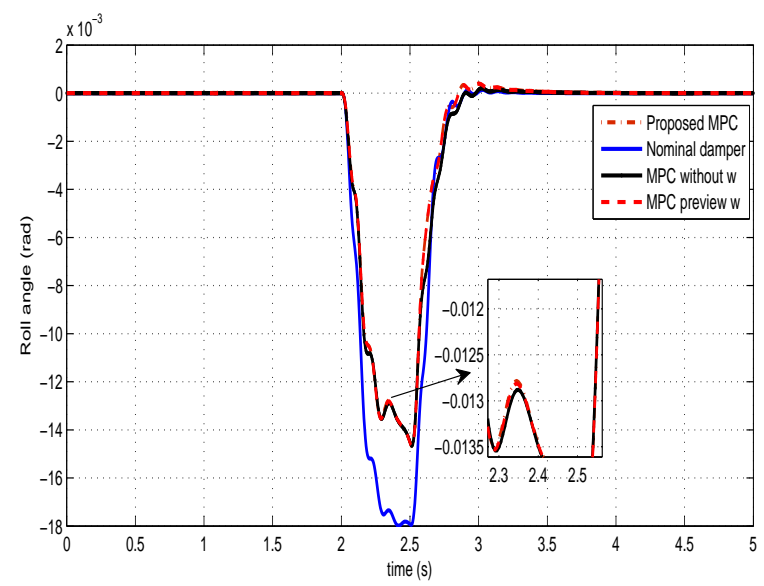

Fig. 6. Roll angle

reduces the roll motion. Here, one has almost the same behavior of Proposed MPC and MPC preview w, and a very slightly improvement with respect to MPC without w.

The dissipativity conditions of the semi-active dampers is also ensured as seen Fig 7.

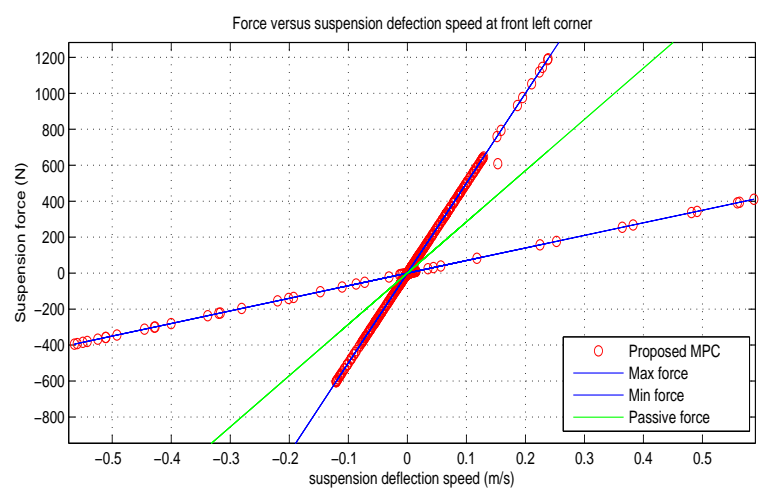

Fig. 7. Damper force versus the deflection speed

Fig 8 describes the suspension forces at front left corner. It shows that when the bump occurs at $t=0.5 \mathrm{~s}$, the suspension is set to be soft to reduce the shock and then, after the bump, the suspension is harder to limit the movement of the vehicle. This allows to enhance the behavior of the vehicle.

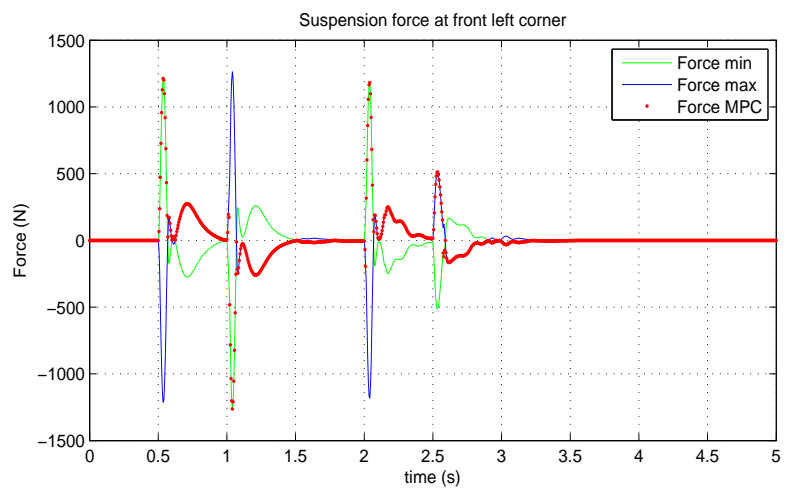

Fig. 8. Front left suspension force
Now, a deeper analysis is provided. Simulations are carried out using benchmark road profiles employed in standard industrial tests. In particular, the following road profiles (see fig. 9) are taken into account:

- ISO road A (smooth runway), vehicle runs at $130 \mathrm{~km} / \mathrm{h}$

- ISO road D (rough runway), maximum amplitude of $0.015 \mathrm{~m}$ and run at $90 \mathrm{~km} / \mathrm{h}$

- A random road profile for comfort test, run at $60 \mathrm{~km} / \mathrm{h}$.
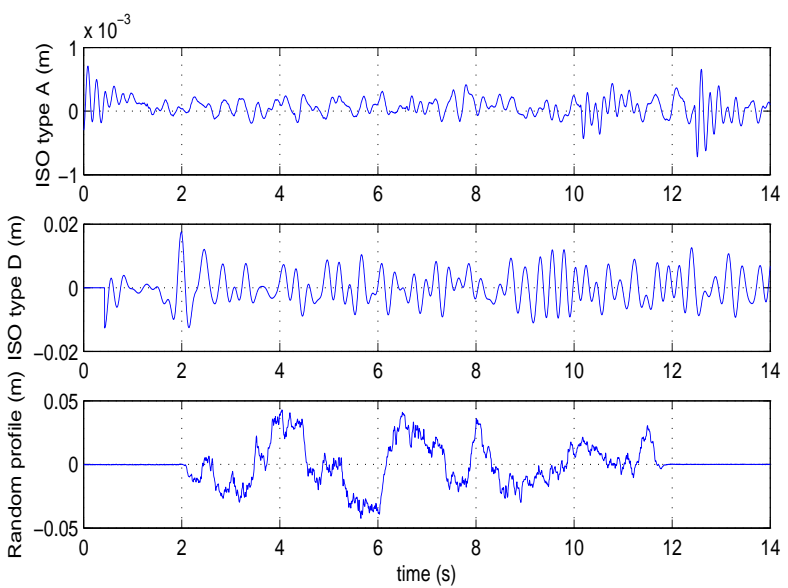

Fig. 9. Different benchmark road profiles

The simulation is performed during $14 \mathrm{~s}$. To evaluate the effectiveness of each approach, the RMS (root mean square) of the chassis acceleration $\left(\ddot{z}_{s}\right)$ is computed and results are presented in table I:

TABLE I

RMS OF CHASSIS ACCELERATION FOR DIFFERENT ROAD PROFILES

\begin{tabular}{|l|l|l|l|}
\hline & $\begin{array}{l}\text { Proposed } \\
\text { MPC }\end{array}$ & MPC preview w & MPC without w \\
\hline ISO road A & 0.0091 & 0.0091 & 0.0102 \\
\hline ISO road D & 0.8140 & 0.7678 & 0.9129 \\
\hline Random road & 0.7582 & 0.7542 & 0.8454 \\
\hline
\end{tabular}

As shown, in the context of semi-active suspensions it seems that MPC road preview does not introduce significant improvements with respect to MPC using road disturbance estimation, moreover, the feedforward action obtained by the MPC disturbance estimation introduces improvements over the case of absence of disturbance compensation (MPC without $\mathrm{w}$ ). This demonstrates one again the interest of the proposed approach.

\section{CONCLUSION}

In this work, a single MIMO state feedback control was designed for the semi-active suspension system of a full vertical vehicle using a MPC strategy. An observer was designed to estimate the system states and the road disturbances. The effects of the disturbances were taken into account in the control design step. The simulation results demonstrate the effectiveness of the presented approach. Thanks to predictive control techniques, multi-objective problems were considered where the control laws were computed to improve the 
passenger comfort and the road handling, while ensuring dissipativity constraints. For the future works, the implementation of this strategy on a testbed, available at Gipsa-lab Grenoble, will be made. It consists of a vehicle equipped with four controllable Electro-Rheological dampers, and of 4 DC motors generating separately different road profiles on each wheel.

\section{REFERENCES}

[1] H. E. Tseng and D. Hrovat, "State of the art survey: active and semiactive suspension control," Vehicle System Dynamics, vol. 53, no. 7, pp. 1034-1062, 2015.

[2] C. Poussot-Vassal, C. Spelta, O. Sename, S. M. Savaresi, and L. Dugard, "Survey and performance evaluation on some automotive semi-active suspension control methods: A comparative study on a single-corner model," Annual Reviews in Control, vol. 36, no. 1, pp. 148-160, 2012.

[3] D. Karnopp, M. J. Crosby, and R. Harwood, "Vibration control using semi-active force generators," Journal of Engineering for Industry, vol. 96, no. 2, pp. 619-626, 1974.

[4] M. Ahmadian, X. Song, and S. C. Southward, "No-jerk skyhook control methods for semiactive suspensions," Journal of vibration and acoustics, vol. 126, no. 4, pp. 580-584, 2004.

[5] S. M. Savaresi and C. Spelta, "Mixed sky-hook and add: Approaching the filtering limits of a semi-active suspension," Journal of dynamic systems, measurement, and control, vol. 129, no. 4, pp. 382-392, 2007.

[6] A. Unger, F. Schimmack, B. Lohmann, and R. Schwarz, "Application of lq-based semi-active suspension control in a vehicle," Control Engineering Practice, vol. 21, no. 12, pp. 1841-1850, 2013.

[7] C. Poussot-Vassal, O. Sename, L. Dugard, P. Gaspar, Z. Szabo, and J. Bokor, "A new semi-active suspension control strategy through LPV technique," Control Engineering Practice, vol. 16, no. 12, pp. 15191534, 2008.

[8] S. M. Savaresi, C. Poussot-Vassal, C. Spelta, O. Sename, and L. Dugard, Semi-active suspension control design for vehicles. Elsevier, 2010.

[9] M. Q. Nguyen, J. M. Gomes da Silva Jr, O. Sename, and L. Dugard, "A state feedback input constrained control design for a 4-semi-active damper suspension system: a quasi-LPV approach," in Proceedings of the 8th IFAC ROCOND, 2015.

[10] N. Giorgetti, A. Bemporad, H. E. Tseng, and D. Hrovat, "Hybrid model predictive control application towards optimal semi-active suspension," International Journal of Control, vol. 79, no. 05, pp. 521533, 2006.

[11] M. Canale, M. Milanese, and C. Novara, "Semi-active suspension control using fast model predictive control," Control Systems Technology, IEEE Transactions on, vol. 14, no. 6, pp. 1034-1046, 2006.

[12] C. Poussot-Vassal, S. M. Savaresi, C. Spelta, O. Sename, and L. Dugard, "A methodology for optimal semi-active suspension systems performance evaluation," in Decision and Control (CDC), 2010 49th IEEE Conference on. IEEE, 2010, pp. 2892-2897.

[13] C. Gohrle, A. Schindler, A. Wagner, and O. Sawodny, "Model predictive control of semi-active and active suspension systems with available road preview," in Control Conference (ECC), 2013 European. IEEE, 2013, pp. 1499-1504.

[14] _ "Road profile estimation and preview control for low-bandwidth active suspension systems," Mechatronics, IEEE/ASME Transactions on, vol. 20, no. 5, pp. 2299-2310, 2015.

[15] C. Poussot-Vassal, O. Sename, L. Dugard, P. Gaspar, Z. Szabo, and J. Bokor, "Attitude and handling improvements through gainscheduled suspensions and brakes control," Control Engineering Practice, vol. 19, no. 3, pp. 252-263, 2011.

[16] U. Kiencke and L. Nielsen, "Automotive control systems: for engine, driveline, and vehicle," Measurement Science and Technology, vol. 11, no. 12 , p. $1828,2000$.

[17] D. Q. Mayne, J. B. Rawlings, C. V. Rao, and P. O. Scokaert, "Constrained model predictive control: Stability and optimality," $A u$ tomatica, vol. 36, no. 6, pp. 789-814, 2000.

[18] A. Bemporad and M. Morari, "Control of systems integrating logic, dynamics, and constraints," Automatica, vol. 35, no. 3, pp. 407-427, 1999.

[19] J. Lofberg, YALMIP. [Online]. Available: http://users.isy.liu.se/johanl/ yalmip/
[20] GurobiOptimization, "Gurobi optimization solver," URL: http://www. gurobi. com, 2012.

[21] D. Q. Mayne, S. Raković, R. Findeisen, and F. Allgöwer, "Robust output feedback model predictive control of constrained linear systems," Automatica, vol. 42, no. 7, pp. 1217-1222, 2006.

[22] C. Gohrle, A. Wagner, A. Schindler, and O. Sawodny, "Active suspension controller using mpc based on a full-car model with preview information," in American Control Conference (ACC), 2012. IEEE, 2012, pp. 497-502. 